\title{
ARTICLE The emergence of pathogenic TNF/iNOS producing dendritic cells (Tip-DCs) in a malaria model of acute respiratory distress syndrome (ARDS) is dependent on CCR4
}

\author{
Bruno Galvão-Filho ${ }^{1,2}$, Júlia Teixeira de Castro², Maria Marta Figueiredo², Claudio Gonçalves Rosmaninho², \\ Lis Ribeiro do Valle Antonelli ${ }^{3,1}$ and Ricardo Tostes Gazzinelli $i^{2,4,5}$
}

\begin{abstract}
Malaria-associated acute respiratory distress syndrome (MA-ARDS) and acute lung injury (ALI) are complications that cause lung damage and often leads to death. The MA-ARDS/ALI is associated with a Type 1 inflammatory response mediated by T lymphocytes and IFN- $\gamma$. Here, we used the Plasmodium berghei NK65 (PbN)-induced MA-ALI/ARDS model that resembles human disease and confirmed that lung $\mathrm{CD}^{+}$and $\mathrm{CD}^{+} \mathrm{T}$ cells predominantly expressed Tbet and IFN- $\gamma$. Surprisingly, we found that development of MA-ALI/ARDS was dependent on functional CCR4, known to mediate the recruitment of Th2 lymphocytes and regulatory T cells. However, in this Type 1 inflammation-ARDS model, CCR4 was not involved in the recruitment of T lymphocytes, but was required for the emergence of TNF-a/iNOS producing dendritic cells (Tip-DCs) in the lungs. In contrast, recruitment of Tip-DCs and development of MA-ALI/ARDS were not altered in $\mathrm{CCR}^{-1-}$ mice. Importantly, we showed that NOS2 ${ }^{-1-}$ mice are resistant to $\mathrm{PbN}$ induced lung damage, indicating that reactive nitrogen species produced by Tip-DCs play an essential role in inducing MA-ARDS/ ALI. Lastly, our experiments suggest that production of IFN- $\gamma$ primarily by $C D 8^{+} \mathrm{T}$ cells is required for inducing Tip-DCs differentiation in the lungs and the development of MA-ALI/ARDS model.
\end{abstract}

Mucosal Immunology (2019) 12:312-322; https://doi.org/10.1038/s41385-018-0093-5

\section{INTRODUCTION}

Malaria is a major public health problem and according to the World Health Organization (WHO) affects more than 200 million individuals and kills over 600,000 children each year. ${ }^{1}$ Parasitized red blood cells (RBC) release pathogen associated molecular patterns and danger associated molecular patterns, which lead to systemic inflammation that is largely responsible for various signs of disease as well as tissue associated pathology, in the lungs, kidney, and placenta. ${ }^{2}$ The acute respiratory distress syndrome (ARDS) and acute lung injury (ALI) are normally related to influenza infection, ${ }^{3,4}$ but may also be a complication of either Plasmodium falciparum ${ }^{5,6}$ and $P$. vivax ${ }^{7,8}$ infections in humans. $5,9,10$ Like in other severe forms of malaria, MA-ARDS/ALI seems to be related to sequestration of Plasmodium infected erythrocytes in the lungs. ${ }^{11}$

Different studies have shown that the molecule CCR4 is a known chemokine receptor for CCL17 and CCL22 and is classically involved in the recruitment of Th2 lymphocytes that mediate lung pathology in asthma and allergic reactions. ${ }^{12,13}$ In addition, CCL17 and CCL22 mediate infiltration of CCR4-expressing regulatory $T$ cells (Treg) promoting immunological escape during tumor development ${ }^{14}$ as well as viral infection. ${ }^{15}$ CCR4 were demonstrated to be able to recognize high concentrations of others putative ligands like $\mathrm{CCL} 2, \mathrm{CCL} 3$, and CCL5 chemokines. ${ }^{16}$ The C57BL/6 mice infected with the NK65 strain of $P$. berghei $(P b N)$ have been used as a model for MA-ARDS/ALI. ${ }^{17}$ In this model, sequestration of infected erythrocytes and the presence of hemozoin are related with lung tissue damage similar to human disease. ${ }^{11,18}$ Likewise, biochemical alterations in the lipid composition of surfactant also contribute to lung inflammation and damage, ${ }^{19}$ whereas heme oxigenase- 1 protects $P$. berghei ANKA $(P b A)$-infected in mice against MA-ARDS/ALI. ${ }^{20}$ Others studies focusing on immunological mechanisms shows that $\mathrm{CD}^{+} \mathrm{T}$ lymphocytes and IFN- $\gamma$ responses are central components in the immunologic mechanisms that mediate pathology in the lungs and other local and systemic complications as well as lethality. ${ }^{21,22}$

Monocytes are highly plastic cells and capable to differentiate into dentritic cells (DC) upon infectious challenge. ${ }^{23,24}$ In a previous study, we demonstrated that infection with $P b A$ promotes the differentiation of splenic monocyte derived dendritic cells (MO-DCs), which are then recruited to the CNS and mediate cerebral malaria in a CCR5-dependent manner. ${ }^{25}$ In this study, we sought to evaluate the role of MO-DCs in MA-ARDS/ $A L I$. We found that MO-DCs are not only a main component of the inflammatory infiltrate, but play a major role in lung tissue

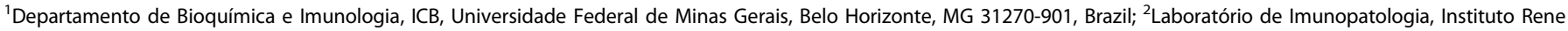

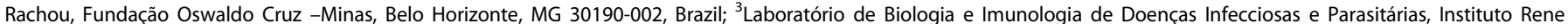

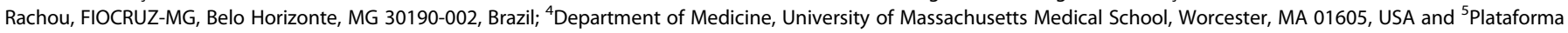
de Medicinal Translacional-Fundação Oswaldo Cruz/Faculdade de Medicina de Ribeirão Preto-Universidade de São Paulo, Ribeirão Preto, SP 14049-900, Brazil Correspondence: Ricardo Tostes Gazzinelli (ritoga@minas.fiocruz.br)

These authors contributed equally: Lis Ribeiro do Valle Antonelli, Ricardo Tostes Gazzinelli.
}

Received: 9 March 2018 Revised: 2 September 2018 Accepted: 10 September 2018

Published online: 18 October 2018 
damage observed in $P b N$ infected mice. Intriguingly, we found that in this MA-ARDS/ALI model, functional CCR4 is required for promoting MO-DC recruitment and lung tissue damage mediated by Th1 immune response. Once in the lungs MO-DCs acquire the potential to produce TNF-a e iNOS, becoming Tip-DCs, which are the effector cells that mediate tissue damage and lethal MA-ARDS/ ALI.

\section{MATERIALS AND METHODS}

Ethics statement

Experiments with mice were conducted according to institutional guidelines for animal ethics and approved by the institutional ethic committees from Oswaldo Cruz Foundation (Fiocruz-Minas, CEUA/LW14/15).

Mice

C57BL/6 mice, $\mathrm{CCR}^{-1-}{ }^{-} \mathrm{CCR}^{-1-}, \beta 2$-microglobulin ${ }^{-1-}, \mathrm{IFN}^{-\gamma^{-/-}}$, and $\mathrm{NOS2}^{-1-}$ were bred and maintained in microisolators at Fiocruz-Minas for 4 weeks until the use. TNFR $1^{-1-}$ mice were kindly provided by Dr. Leda Quercia from Departament of Biochemistry and immunology (Universidade Federal de Minas Gerais). Female and male mice between 6 to 10 weeks old were used in all experiments.

\section{Plasmodium berghei NK65 $(\mathrm{PbN})$ infection}

The $P b N$ used in our experiments is originally from the Department of Parasitology at New York University and was obtained from Dr. Antoniana Krettli laboratory at Centro de Pesquisas René Rachou - Fiocruz. Briefly, $P b N$ strain was maintained in Swiss mice by maximum of eight serial blood passages once-twice week, when parasitemia reached $3-4 \%$ of iRBCs. Parasites were then transferred to $\mathrm{C} 57 \mathrm{BL} / 6$, before experimental groups were infected with $\mathrm{PbN}$. Wild type C57BL/6 and knockout mice in the $\mathrm{C} 57 \mathrm{BL} / 6$ genetic background were infected i.p. with $10^{4}$ iRBCs diluted in PBS $1 \times$. All mice received paraminobenzoic acid 3 days before experimental challenge to improve parasite growth. ${ }^{26,27}$

\section{Lung extraction and leukocytes isolation}

Uninfected and infected mice at different days post-infection were anesthetized, perfused with $20 \mathrm{ml}$ of PBS by right ventricular puncture, lungs harvested and placed on ice. The lungs were then spliced with scissors and incubated with liberase (Sigma, St. Louis, MO) for $60 \mathrm{~min}$ at $37^{\circ} \mathrm{C}$. The lungs were passed through a $100 \mu \mathrm{m}$ nylon cell strainer to separate single cells. The resulting cell suspensions were centrifuged and the pellet was suspended in $35 \%$ Percoll solution. ${ }^{28}$ After a new centrifugation at $2500 \mathrm{rpm}$ for $20 \mathrm{~min}$, the supernatant with lung cells were discarded and pellet containing leukocytes suspended in ACK buffer to lyse RBC. The purified white blood cells were then washed and suspended in RPMI 1640 medium supplemented with penicillin, streptomycin, and $5 \%$ fetal bovine serum (Gibco, ThermoFisher, Waltham, MA) and processed to be used in our experiments.

\section{Evaluation of lung damage and histopathology}

The lungs were harvested after being perfused from infected and control mice. Lungs were placed on a flat device and pictures were taken for macroscopic evaluation of edema and blood presence. Added to this, the lung biopsies were fixed in $10 \%$ neutral buffered formalin $(\mathrm{pH} 7.2)$ for at least $78 \mathrm{~h}$. Samples were then dehydrated, cleared, embedded in paraffin, sectioned at 3-4 $\mu \mathrm{m}$ thick and stained with hematoxylin and eosin (HE) for histopathological studies through the an optic BX53 Biological microscope equipped with Camera Qcolor5 -Ollympus. All biopsies were retained and assessed histologically. Chronic inflammatory reactions in samples were based on the presence or absence of plasma cells, macrophages (epithelioid cells and giant cells), lymphocytes, and unorganized or organized granulomas. Some parameters were evaluated such as thickening of bronchi and pleura, perivascular inflammatory infiltrate, edema and alveolar infiltrate, hemorrhage, atelectasis and pulmonary necrosis, bronchial occlusion, and a frequency of polymorphonuclear cells (neutrophils and eosinophils) in stained slides. HE staining was also used to characterize the semi-quantitative procedure (slight to intense). The scoring system was based on previously report ${ }^{17}$ with modifications, as follow: $0=$ does not display, no injury (apparently histologically normal tissue); 1 = discrete and slight, when the lesion occupies less than $25 \%$ of the tissue; $2=$ moderate when the lesion occupies $25-50 \%$ of the tissue; and $3=$ intense, a severe injury with diffuse or focal inflammation around all structure of biopsy occupying more than $50 \%$ of the tissue.

The permeability were evaluated by Evans blue dye (2\% in PBS, $100 \mu \mathrm{l})$, which was injected intraveneously and $1 \mathrm{~h}$ later, the lungs were perfused and dissected. The lungs were homogenized in PBS $(100 \mu \mathrm{g}$ tissue $/ \mathrm{ml})$, mixed with 2 volumes formamide and incubated at $60^{\circ} \mathrm{C}$ for $24 \mathrm{~h}$. After centrifugation, the Evans blue concentration in the extract was determined by measurement of the absorbance at $630 \mathrm{~nm}$ and comparison with a standard dilution curve.

qPCR

RNA was extracted from lungs of control and infected mice with Trizol reagent (Invitrogen), transcribed to CDNA, and primers for CCL2 (F 5-TGGCTCAGCCAGATGCAGT-3, R 5-TTGGGATCATCTTG CTGGTG-3), CCL4 (F 5-TCTTGCTCGTGGCTGCCT-3, R 5-GGGAGGGTC AGAGCCCA-3), CCL5 (F 5-CAAGTGCTCCAATCTTGCAGTC-3, R 5-Tा CTCTGGGTTGGCACACAC), CCL17 (F 5-CAGGGATGCCATCGTGTT C-3, R 5-CACCAATCTGATGGCCTTCTT-3), CCL22 (F 5-TACATCCGTC ACCCTCTGCC-3, R 5-CGGTTATCAAAACAACGCCAG-3), CXCL9 (F 5-A ATGCACGATGCTCCTGCA-3， R 5-GGTCTITGAGGGATTTGTAGTG-3) and CXCL10 (F 5-GCCGTCATITCTGCCTCA-3, R 5-CGTCCTTGCGAG AGGGATC-3) (Integrated DNA Technologies) used to quantify gene expression by PCR.

DNA from lungs of $P b N$-infected mice was extracted by illustra tissue \& cells genomicPrep Mini spin kit (GE Healthcare). The primers of mouse endogenous gene, GAPDH (Forward: GGCAAATTCAACGGCACAGT and Reverse: AGATGGTGATGGGCTTCCC) and the Plasmodium berghei $18 \mathrm{~s}$ ribosomal $18 \mathrm{~s}$ gene (Forward: AAGCATTAAATAAAGCGAATACATCCTTA and $18 \mathrm{~s}$ Reverse: GGAGATTGGTITTGACGTTTATGT) were used to determine the parasite load in the lungs by relative quantification, normalized with the mouse GAPDH $(\triangle C T)$. The quantitative PCRs were carried out with the Platinum SYBR Green protocol (Invitrogen) on an Applied Biosystems 7500 real-time PCR system.

\section{Flow cytometry}

Isolated leukocytes from lungs of uninfected control as well as infected mice were stained with labeled monoclonal antibodies (mAbs) specific for cell surface markers or intracellular transcription factors or cytokines. mAbs for flow cytometry specific for CD11c (-Alexa-fluor 700), CD11b (-PECy7 or -APCCy7), MHCII (-PE), F4/80 (-PerCP-Cy5.5), DCsign (-APC), CD8(-APCCy7 -PECy5), CD4 (-FITC), Ly6c (-efluor-450), CD80 (-PE), CD86 (-PECy5), CD115 (-FITC), CD3 (-FITC), and CD3 (-efluor-450) were obtained from eBioscience and CD68 (-biotinylated plus streptavidin conjugated with Qdot605) was obtained from Invitrogen. The intracellular fixation and permeabilization buffer set of eBioscience was used to perform IFN- $\gamma$-APC, TNF- $\alpha-P E$, and NOS2-PE. To Tbet-PE, GATA3-PE, RORYT-PE, and Foxp3-PE transcription factors staining the Foxp3 staining buffer set was used (eBioscience).

Cytokine measurements

Cytokine levels were measured in the supernatant of macerated lungs homogenate from $\mathrm{PbN}$-infected and control mice by using 
314

the commercially available ELISA Duoset kit from Becton \& Dickson (Franklin Lakes, NJ).

Statistical analysis

All data were analyzed using Graphpad Prism 5.0 Software. The differences between two groups were verified using $t$ test or Mann-Whitney test for parametric or nonparametric data, respectively. For analysis with more than two groups we used ANOVA or Kruskal-Wallis for parametric or nonparametric data, respectively. Differences were considered statistically significant when $p<0.05$.

\section{RESULTS}

CCR4 deficient mice do not develop lethal MA-ARDS/ALI

Consistent with previous studies infection with $\mathrm{PbN}$ caused MAARDS/ALI in C57BL/6 mice. ${ }^{17}$ The results presented in Fig. 1a show that CCR4 deficient mice infected with $P b N$ are protected from pronounced lung damage when compared to wild type (WT) mice, as indicated by macroscopic phenotype (left panel) and evans blue staining (right panel and graph). Because lung weight is augmented due to edema and cell infiltrate, we measured lungs weight in controls and $P b N$ infected animals. Indeed, the lungs from infected WT mice are heavier than lungs from infected $\mathrm{CCR}^{-1-}$ mice (Fig. 1b). In addition, lungs from $\mathrm{PbN}$-infected mice were dissected at 9 days post-infection, sections stained with hematoxylin-eosin and evaluated as indicated in material and methods. The histopathological analysis indicates that CCR4 ${ }^{-1-}$ mice are resistant to MA-ARDS/ALI. Hemorragy, edema, infiltrate of pleura and thickening of pleura, arterioles and alveolus were significantly higher when comparing WT and $\mathrm{CCR}^{-1-}$ mice infected with $\mathrm{PbN}$ (Figure S1). In contrast, we observed that parasitaemia was similar in WT and $\mathrm{CCR}^{-1-}$ mice, up to 10-12 days post-infection, before the death of WT mice (Fig. 1d).

Consistent with histopathology findings, $\mathrm{CCR} 4^{-1-}$ mice were more resistant to $P b N$ induced lethality than WT mice that is observed around 10 days post-infection (Fig. 1e). Furthermore, experiments with bone marrow transfers indicate that early lethality in $\mathrm{PbN}$-infected mice is mediated by hematopoietic cells, since chimeric WT mice that received CCR4 ${ }^{-1-}$ hematopoietic cells did not developed MA-ARDS/ALI (Fig. 1f) and the majority of $\mathrm{CCR}^{-1-}$ mice that received bone marrow cells from WT donors died until 12 days post-infection (Fig. 1g).

CCR4 mediated tissue pathology in the lung is associated with the presence of Tbet-expressing $T$ lymphocytes

A previous study employing $P b N$ mouse model of MA-ARDS/ALI shows that depletion of $\mathrm{CD}^{+} \mathrm{T}$ cells protects mice from lung damage and lethality. ${ }^{17}$ We observed that $\mathrm{CD}^{+} \mathrm{T}$ cells from either uninfected or infected mice express CCR4, whereas CD4 ${ }^{+} \mathrm{T}$ lymphocyte did not. Furthermore, both activated $\mathrm{CD}^{+}{ }^{+} \mathrm{T}$ and $\mathrm{CD}^{+} \mathrm{T}$ from infected mice expressed CXCR3 (Fig. 2a). The main gate strategies to study $T$ cells were based on the expression of $\mathrm{CD}^{+}, \mathrm{CD}^{+}$, and $\mathrm{CD}^{+}$and the exclusion of $\mathrm{F} 4 / 80$ and $\mathrm{CD} 19$ expressing cells (Figure S2). We evaluated the migration of $T$ lymphocytes and CCR4 deficiency did not impact on $\mathrm{CD}^{+} \mathrm{T}$ cell migration to the lungs of $\mathrm{PbN}$-infected mice (Fig. $2 \mathrm{~b}$ ). Then we performed a kinetics to verify the migration of $T$ cells to the lungs on days $0,3,5,7$, and 9 post $P b N$ infection. We observed an increase in the frequency and numbers of $C D 8^{+}$T cells beginning at day 7 post-infection (Figure S3A and S3B). Furthermore, we demonstrated that CCR4 did not interfere with T cell activation, as indicated by CD44 and CD62L expression (Figure S3C).

Next, we verified the expression of Tbet (Th1 marker), GATA-3 (Th2 marker), RORyt (Th17 marker), and FoxP3 (Treg marker) by $\mathrm{CD}^{+} \mathrm{T}$ and $\mathrm{CD}^{+}{ }^{+}$cells recruited to the lungs of $\mathrm{CCR}^{-/-}$and $\mathrm{WT}$ mice infected with $P b N$ (Figs. $2 c$, d and S4A). We noticed that a high frequency of $\mathrm{CD}^{+}{ }^{+}$and $\mathrm{CD}^{+} \mathrm{T}$ lymphocytes in the lungs of infected mice expressed Tbet. In contrast, the frequency of $\mathrm{CD} 4^{+}$ T cells expressing FoxP3 was decreased in the lungs of infected mice. The frequency of either RORyt-expressing or GATA-3expressing $\mathrm{CD}^{+}{ }^{+} \mathrm{T}$ and $\mathrm{CD}^{+} \mathrm{T}$ were low and not altered in control and infected C57BL/6 mice. The CCR4 deficiency did not impact in the frequency of Tbet, GATA-3, RORyt or FoxP3 positive $T$ lymphocytes in the lungs of control or infected mice. Similar analysis was performed in spleen of control of $\mathrm{PbN}$-infected WT and CCR4 ${ }^{-1-}$. It was observed a dominance of $\mathrm{Tbet}^{+}$as well as FoxP3 $^{+} \mathrm{T}$ cells. The lack of functional CCR4 impacted on the differentiation of Treg $\left(\mathrm{FoxP}^{+}\right)$, but not on $\mathrm{Tbet}^{+}$Th1 or $\mathrm{CD} 8^{+} \mathrm{T}$ lymphocytes (Figure S4B and C).

Increased frequency of iNOS/TNF-a producing monocyte derived dendritic cells (Tip-DC) during MA-ARDS/ALI development

Since no impairement of $T$ cells recruitment, activation and differentiation to the Th1 phenoype was observed, we asked whether the CCR4 deficiency would interfere with the migration of myeloid cells to the lungs of $\mathrm{PbN}$-infected mice. The experiment shows a time dependent increase in the frequency

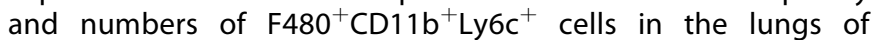
infected C57BL/6 mice (Fig. 3a and S5A). A deeper analysis of monocyte subsets show a high frequency of MO-DC markers, such as CD11C and DCsign, stimulatory molecules MHCII, CD80 and CD86, and a negative expression of the blood monocyte marker CD115, the classical dendritic cells maker CD135 and the macrophage marker CD68 (Fig. 3b). All these DCs markers in Ly6c + and Ly6c - cells were evaluated to medium fluorescence intensity (MFI) as demonstrate in our results (Figure S6A and $\mathrm{S} 6 \mathrm{~B})$. Moreover, we performed an intracellular staining and analyzed by flow cytometry and found a higher frequency of differentiated MO-DC cells expressing TNF- $a$ and iNOS proteins compared to neutrophils and alveolar macrophages (Fig. 3c). These findings indicate that Tip-DC is a dominant DC subset and the main source of reactive nitrogen species in the lung tissue during MA-ARDS/ALI. The total numbers and frequency of other leucocytes in the lungs of infected mice were also evaluated, but we did not detect significant differences when compared to controls (Figure S7A and B).

CCR4, but not CCR2, is involved in MO-DC recruitment to the lungs during MA-ARDS/ALI

Previous studies demonstrate that Tip-DCs migrate to peripheral organs in a CCR2 dependent manner. ${ }^{29}$ The dependency of CCR2 for monocyte functions seems to differ in malaria models depending on infective parasite species or tissue site of pathology that are being evaluated. ${ }^{25,30}$ To verify possible ligands of CCR4 present in the lungs, we performed a qPCR to quantify the expression of CCL2, CCL3, CCL5, CCL17, and CCL22. While CCL5, CCL17, and CCL22 were not expressed in the lungs of $\mathrm{PbN}$-infected mice when compered to uninfected mice, we verified an increased expression of CCL2 and CCL3 by qPCR (Fig. 4a). Consistently, we found high levels of CCL2 protein, both in lungs and serum from $\mathrm{PbN}$-infected mice (Fig. 4b). We also show by representative histogram and quantitative expression by $\mathrm{MFI}$ (graph) that $\mathrm{F} 4 / 80^{+} \mathrm{CD} 11 \mathrm{~b}^{+}$cells constitutively express both CCR2 and CCR4 (Fig. 4c). Because CCR2 is important for monocytes egress from bone marrow, we verified if migration of MO-DC to the lungs is CCR2 and CCR4 dependent. Surprisingly, we found that MO-DC migration to the lungs were profoundly impaired in $\mathrm{CCR}^{-1-}$ mice. In contrast, the frequency of monocytes/MO-DC in the lungs of CCR2 $2^{-1-}$ mice at 9 days post-infection was not affected (Fig. 4d, e). Consistently, $\mathrm{CCR}^{-1-}$ mice have the same survival rate than WT mice, whereas $\mathrm{CCR}^{-1-}$ was more resistant to challenge with $\mathrm{PbN}$ (Figs. 1, 4f). To better understand the CCR4 role in myeloid cells, we performed a kinetic experiments in WT, $\mathrm{CCR}^{-1-}$ and $\mathrm{CCR}^{-1-}$ mice at $0,5,7$, and 9 days post-infection to evaluate 
a WT $\quad \mathrm{CCR}^{-1-} \quad \mathrm{WT} \quad \mathrm{CCR}^{-1-}$
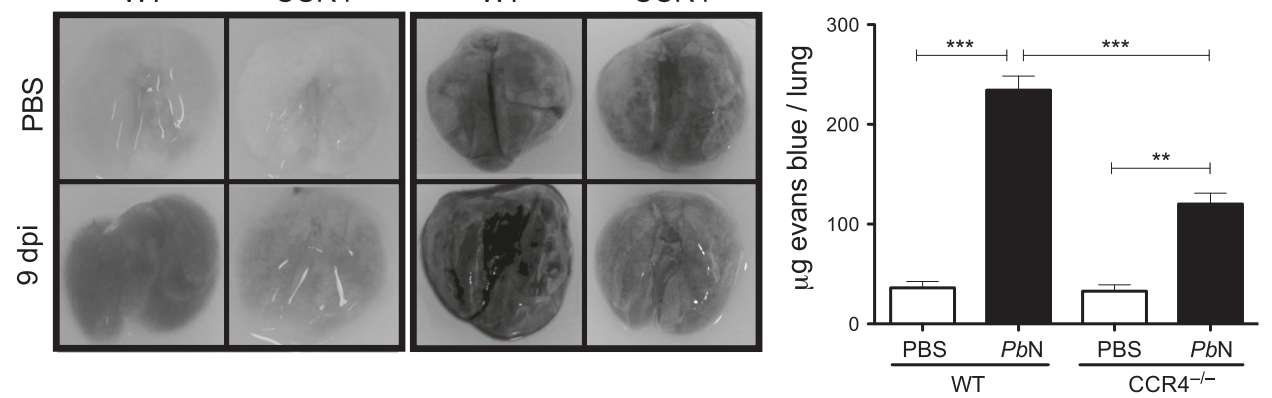

b

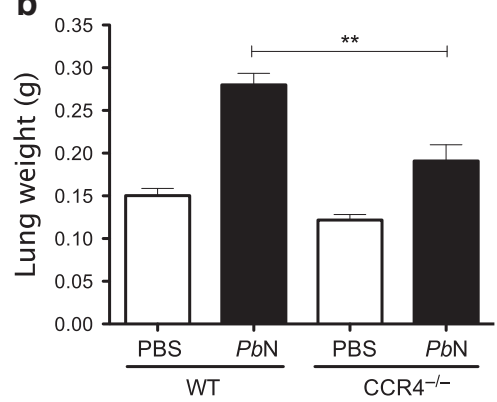

d

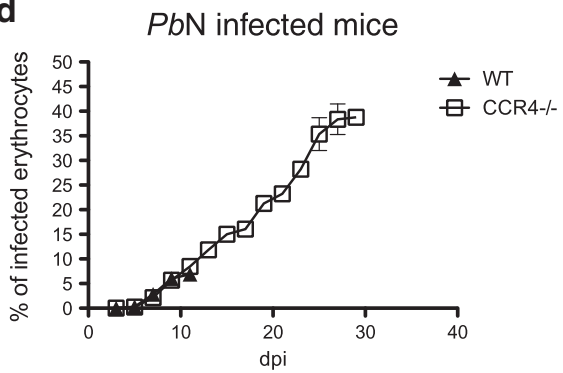

f

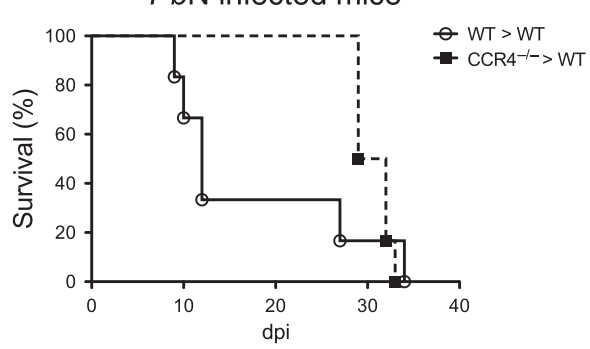

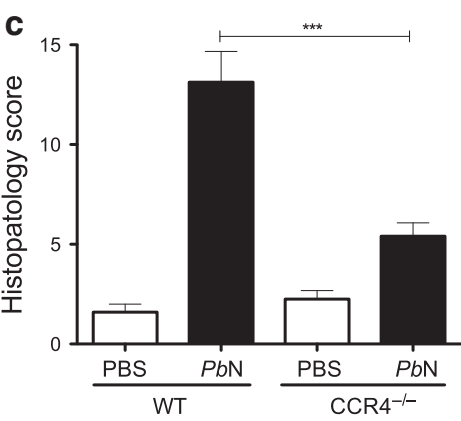

e

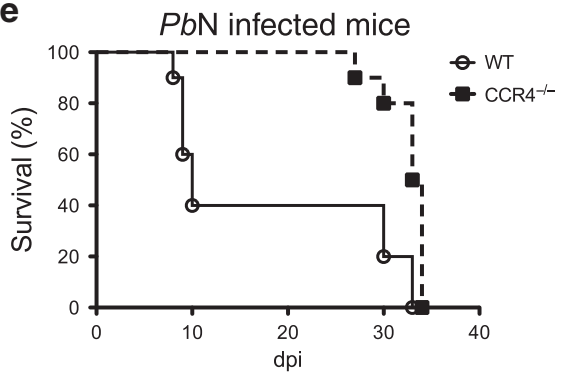

g

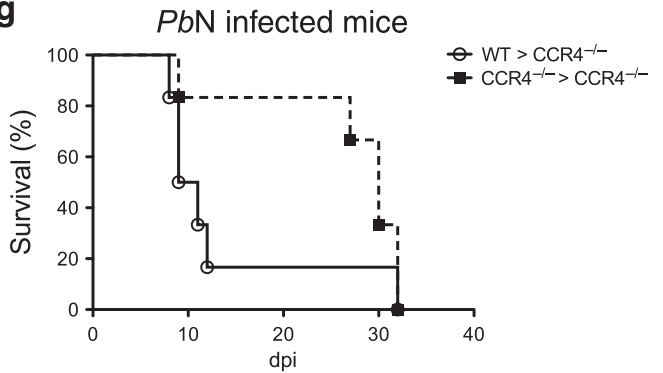

Fig. 1 CCR4 expression on hematopoietic cells is necessary for MA-ARDS/ALI development. a Hemorrhagy (left quadrants) and permeability by evans blue dye (right quadrants) from lungs of uninfected controls (top quadrants) and C57BL/6 and CCR4 ${ }^{-1-}$ mice 9 days post-infection (bottom quadrants). The bar graph indicates the quantification of evans blue infiltrated in the lungs. b Weights of lungs from WT and CCR4 knockout mice were determined at 9 days post-infection. c Histopathology scores, based on edema and inflammatory infiltrate were evaluated after H\&E staining. d Parasitemia of C57BL/6 and CCR4 ${ }^{-1-}$ mice. e Survival of PbN-infected C57BL6 and CCR4 ${ }^{-1-}$ mice. f WT chimera mice reconstituted with bone marrow cells from CCR4 ${ }^{-/-}$or WT control $\left(C C R 4^{+/+}\right)$mice. $\mathbf{g ~ C C R 4}{ }^{-/-}$chimera mice reconstituted with bone marrows from WT or $\mathrm{CCR}^{-1-}$ mice. Data are representative of at least two independent experiments $(n=4-6$ mice per group)

the frequency of monocytes derived cells and neutrophils in the lungs, spleen, and blood. CCR2 ${ }^{-1-}$ mice showed low frequency of monocytic cells in blood and spleen and a delayed recruitment to the lungs. In contrast, the frequencies of monocytes in blood and spleen of $\mathrm{PbN}$-infected $\mathrm{CCR} 4^{-/-}$mice were similar to WT mice, but the recruitment to the lungs was severily impaired. The recruitment of neutrophils to the lungs were increased in $\mathrm{CCR}^{-1-}$ mice at 5,7 , and 9 days postinfection, while not affected in infected $\mathrm{CCR}^{-1-}$ mice (Figure $\mathrm{S} 8 \mathrm{~A}$ and $\mathrm{B}$ ).
$\mathrm{CD}^{+}{ }^{+}$cells- and IFN- $\gamma$-dependent differentiation of Tip-DC during MA-ARDS/ALI

Since $\mathrm{CD}^{+} \mathrm{T}$ lymphocytes and Th1 mediated responses have been shown to play important role on MA-ARDS/ALI development in the $\mathrm{PbN}$ model, we infected IFN- $\gamma^{-/-}$and $\beta 2-$ microglobulin $^{-1-}$ mice and compared the lung damage by macroscopy and lethality. We showed that hemorrhagic lesions (left panel) and lethality (right panel) are dependent of both $\mathrm{CD}^{+} \mathrm{T}$ cells and IFN- $\gamma$ (Fig. $5 \mathrm{a}, \mathrm{b}$ ). CXCR3 is the chemokine receptor for CXCL9 and CXCL10, which are inducible by IFN $-\gamma$ and key chemotactic factors for activated Th1 and 
a

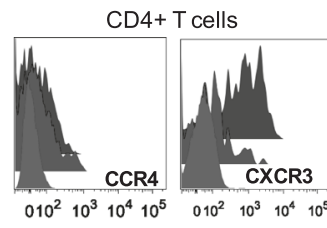

$\mathrm{CD} 8+\mathrm{T}$ cells

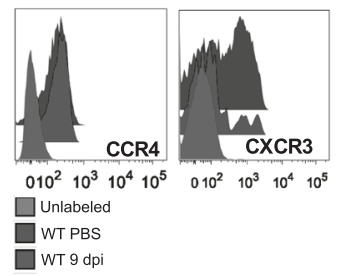

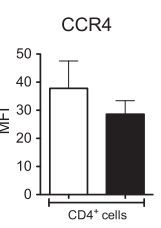

CCR4

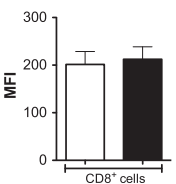

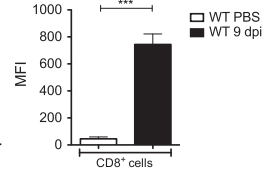

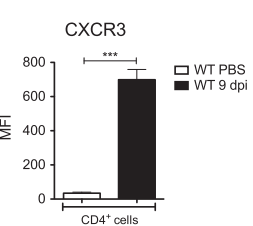

CXCR3

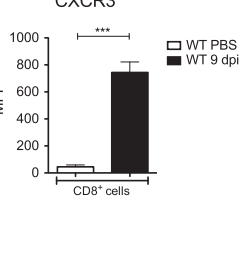

b
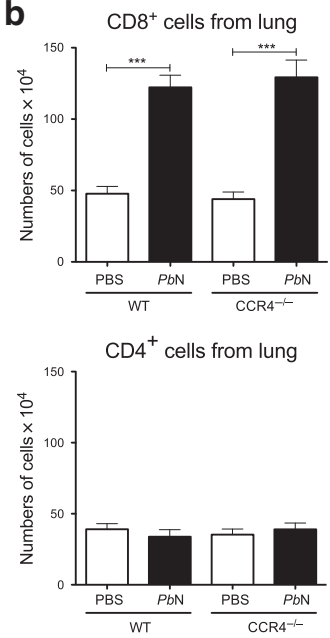
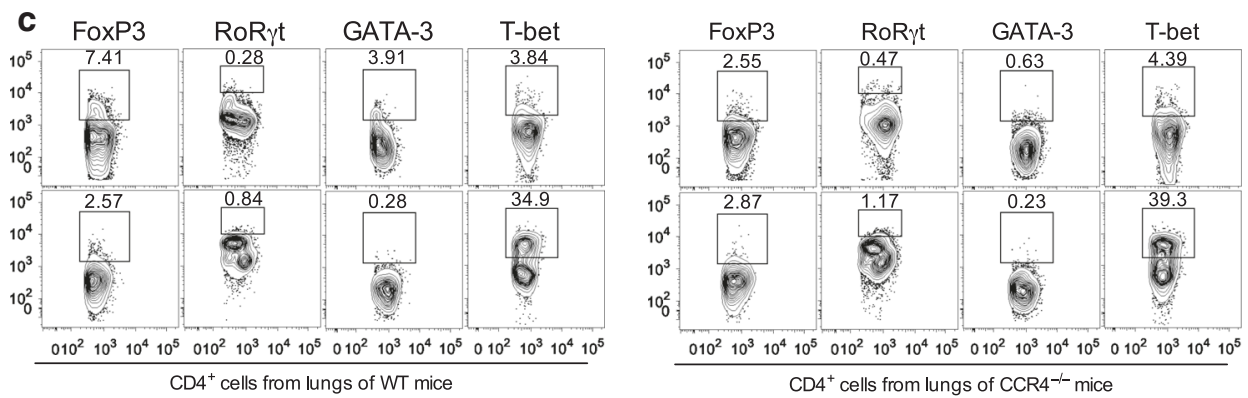

d
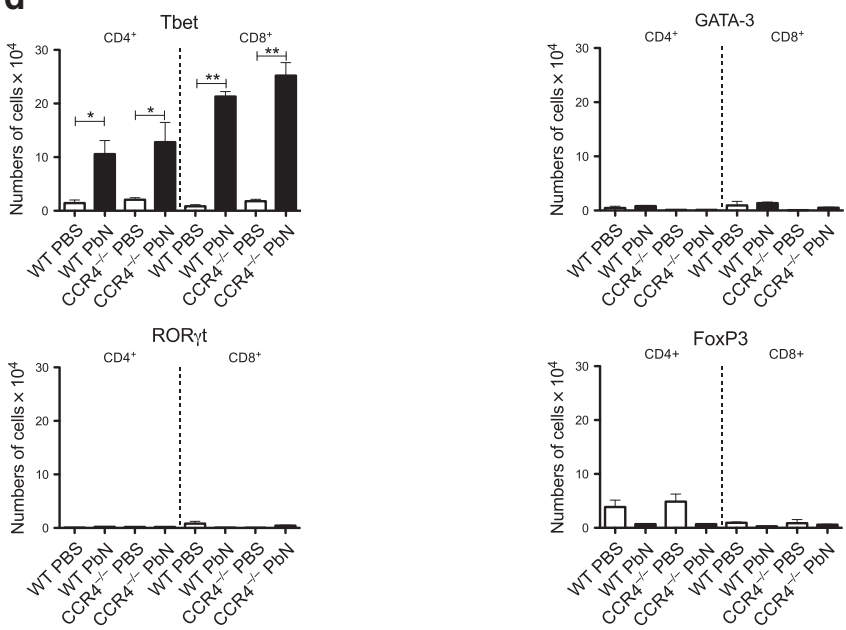

Fig. 2 MA-ARDS/ALI is primarily associated with CXCR3 + and Tbet + T cells. a Expression of CCR4 (left panels) and CXCR3 (right panels) on $\mathrm{CD}^{+} \mathrm{T}$ cells (top panels) or CD8 ${ }^{+} \mathrm{T}$ cells (bottom panels) from uninfected and $\mathrm{PbN}$-infected C57BL/ 6 mice. Graphs indicating MFI of the CCR4 and CXCR3 expression by CD8+ and CD4+ are shown in the right. $\mathbf{b}$ Total number of $\mathrm{CD}^{+}$(top panel) and CD4 ${ }^{+}$(bottom panel) T cells in the lungs of WT and CCR4 ${ }^{--}$mice infected with PbN. c Intracellular staining of the transcription factors Tbet, GATA-3, ROR $\gamma \mathrm{t}$, and FoxP3 in CD4 ${ }^{+}$ T cells from uninfected controls (top panels) or PbN-infected (bottom panels) WT (left panels) and CCR4 ${ }^{-1-}$ mice (right panels). d Total number

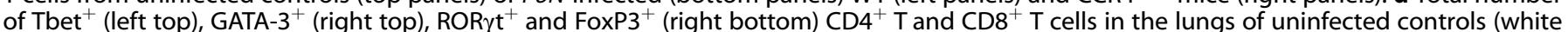
bars) and $\mathrm{PbN}$-infected (black bars) WT and $\mathrm{CCR}^{-1-}$ mice. Data (a-d) are representative of at least two independent experiments $(n=4-6$ mice per group)

$\mathrm{CD}^{+} \mathrm{T}^{+}$lymphocytes. ${ }^{31}$ Hence, we investigated the expression of CXCL9 and CXCL10 in the lungs of infected WT, IFN- $\gamma^{--}$and $\beta 2-$ microglobulin $^{-1-}$ mice. Expression of both CXCL9 and CXCL10 mRNA were decreased in the lungs of both IFN- $\gamma^{-1-}$ and $\beta 2-$ microglobulin $^{-1-}$ infected with PbN (Fig. 5c).

Previous studies have demonstrated that differentiation of $\mathrm{MO}-$ DCs is highly dependent on endogenous IFN- $\gamma^{23,25,32}$ Next, we evaluated the expression of dendritic cell surface markers DCsign
(CD 209) and CD11c surface on $\mathrm{F} 4 / 80^{+} \mathrm{CD} 11 \mathrm{~b}^{+} \mathrm{Ly}_{6 \mathrm{c}^{+}}$cells, in order to verify if differenciation of MO-DCs in the lungs is affected either in IFN- $\gamma^{-1-}$ or $\beta 2$-microglobulin ${ }^{-1-}$ mice (Fig. $5 \mathrm{~d}$, e). In fact, we observed that DCsign and CD11c were not expressed by F4/ $80^{+} \mathrm{CD} 11 \mathrm{~b}^{+} \mathrm{L} \mathrm{c}^{+}$cells in the lungs from IFN $-\gamma^{-1-}$ infected with $\mathrm{PbN}$. In contrast, deficiency of $\beta 2$-microglobulin did not impact on MO-DC differenciation in the lungs of infected mice (Fig. 5d). We also found that high levels of IFN- $\gamma$ and TNF- $\alpha$ are produced in the 


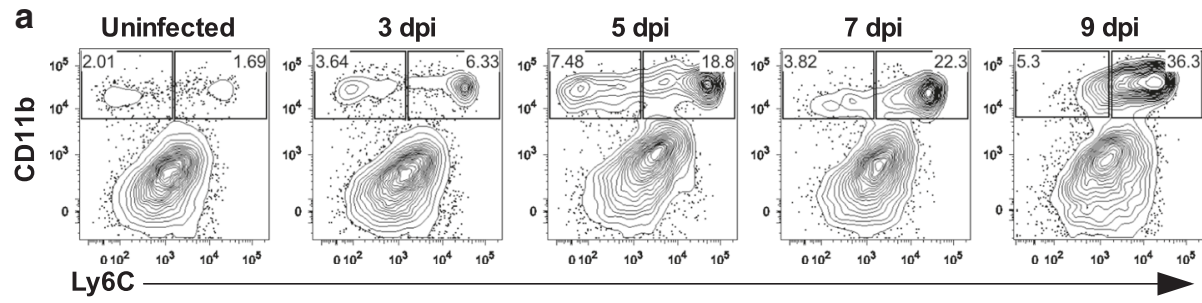

b
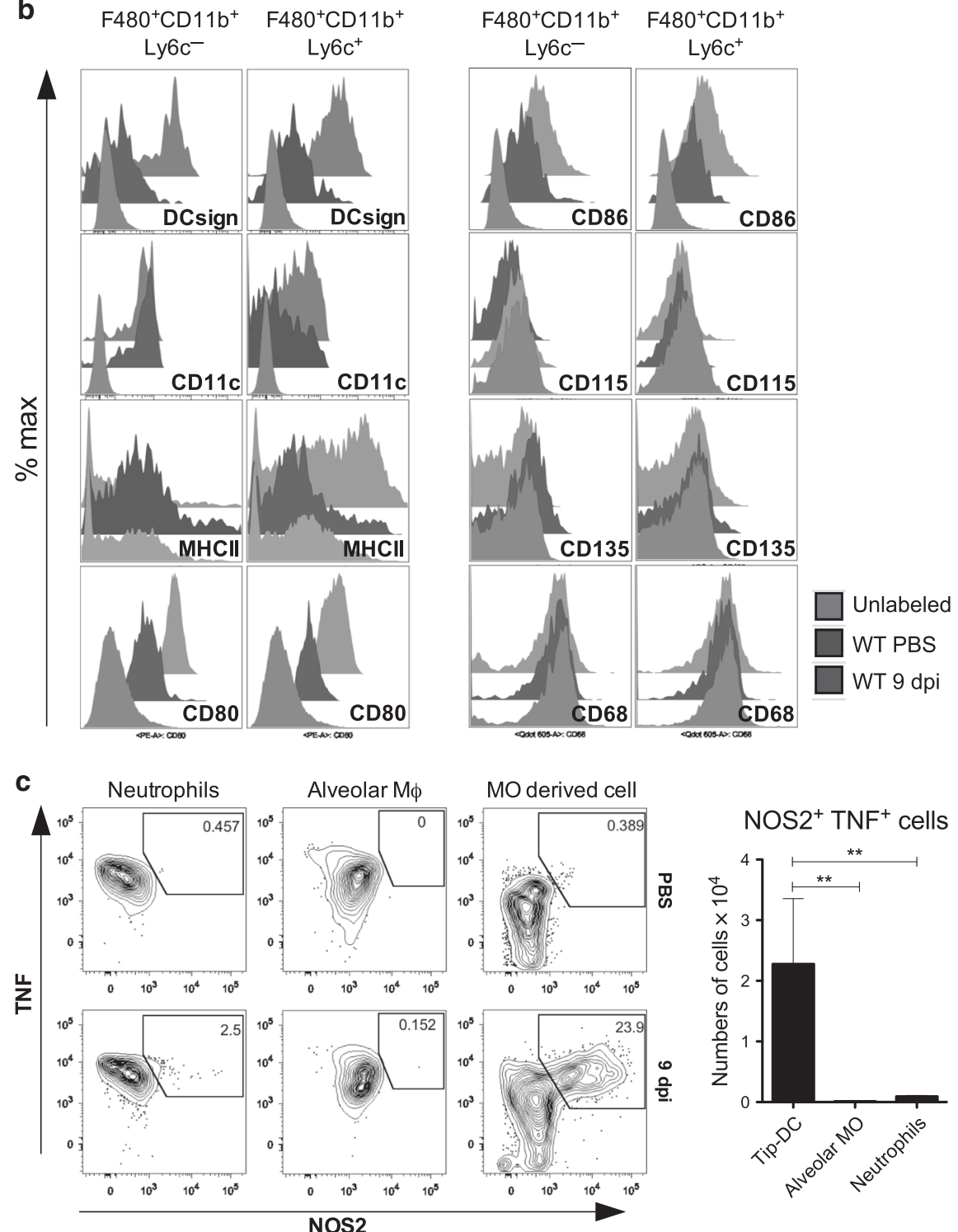

Fig. 3 Emergence of TNF- $\alpha$ and iNOS producing dendritic cells (Tip-DC) in the lungs from PbN infected mice. a Dot plots indicating kinetics of

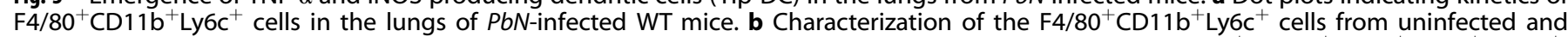
infected WT mice at 9 days post-infection by flow cytometry shows that they are $\mathrm{CD} 68^{-} \mathrm{CD} 115^{-} \mathrm{CD} 135^{-} \mathrm{DCsign}{ }^{+} \mathrm{CD} 11 \mathrm{c}^{+} \mathrm{CD} 80^{+} \mathrm{CD} 86^{+} \mathrm{MHCl}{ }^{+}$. c Intracellular staining of TNF $\alpha$ and NOS2 expression by MO-DC harvested from lungs of $P b N$-infected C57BL/6 mice at 9 days post infection. Dot plots with frequency (left) and graph with total number (right) of Tip-DCs, alveolar macrophages (Alveolar MO) and neutrophils. Data (a-c) are representative of at least two independent experiments $(n=4-6$ mice per group)

lungs of $\mathrm{PbN}$-infected C57BL/6 mice (Fig. 5f). Additionally, our analisys show that both in the lungs and spleens $\mathrm{CD}^{+}$cells represent more than $94 \%$ of IFN- $\gamma$ producing cells (Figure S9A). The intracellular staining also shows that $\mathrm{CD} 8^{+} \mathrm{T}$ cells are the main source of IFN- $\gamma$ in the lungs (Fig. $5 \mathrm{~g}$ ). Importantly, we found that compared to WT mice, the number of Tip-DCs in the lungs of

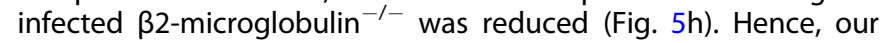

results suggest that differentiation of $\mathrm{MO}-\mathrm{DC}$ into Tip-DC requires production of IFN- $\gamma$ by $\mathrm{CD} 8^{+} \mathrm{T}$ cells. $^{33}$

Requirement of NOS2 expression by Tip-DC for MA-ARDS/ALI development in $\mathrm{PbN}$-infected mice

Finally, the lack of Tip-DCs expressing NOS2 resulted in protection against MA-ARDS/ALI development (Fig. 6a) and lethality during 
a

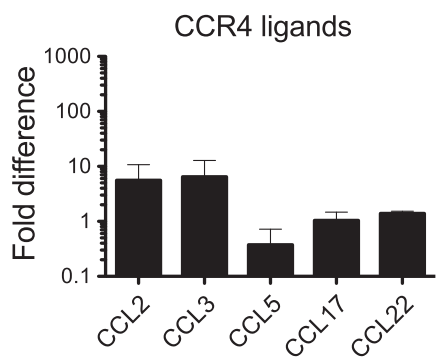

C
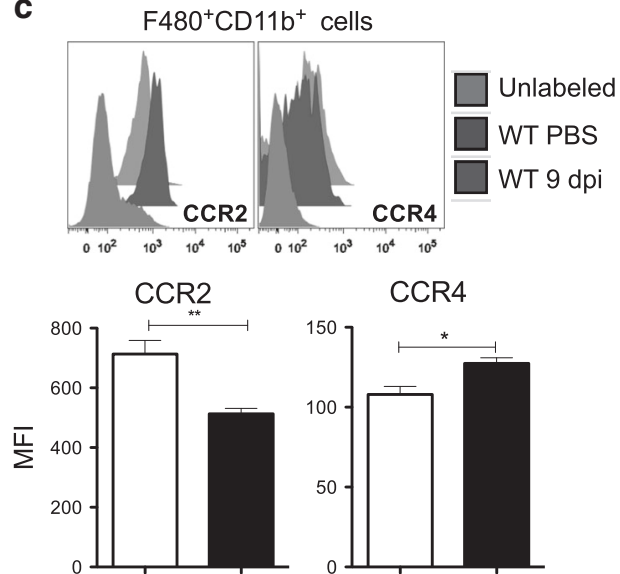

CCR4

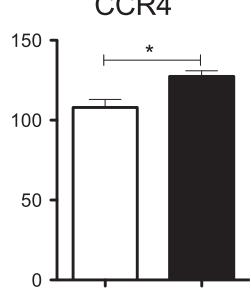

$\square$ WT PBS

WT PbN

e
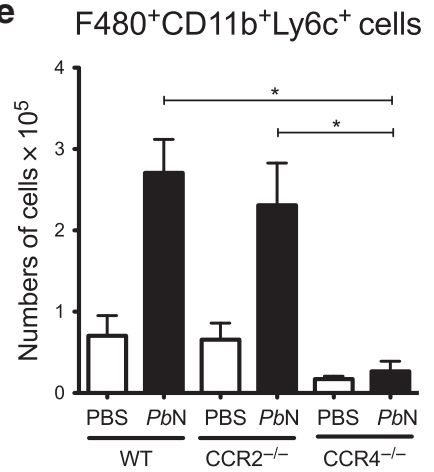
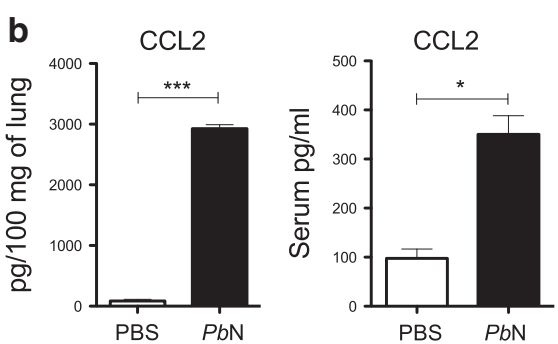

d

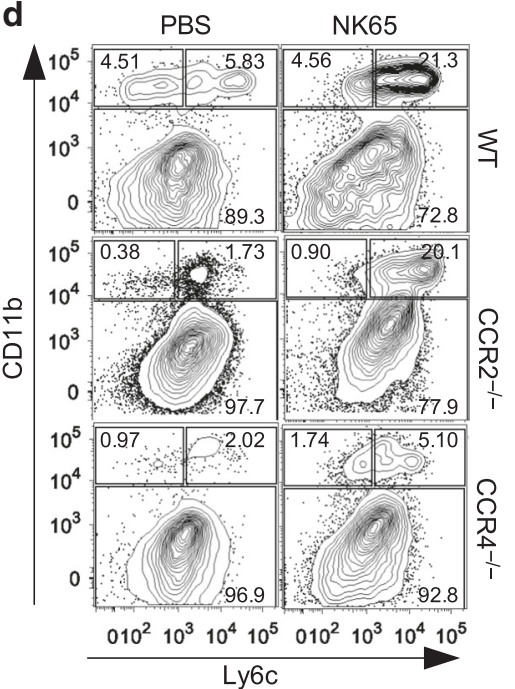

f

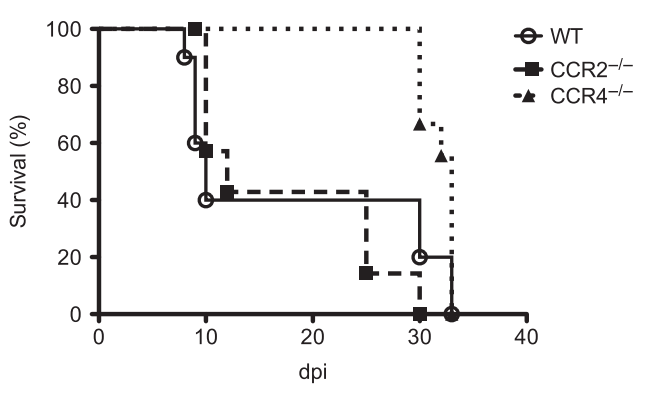

Fig. 4 Emergence of Tip-DCs in the lungs of $P b N$-infected mice is mediated by CCR4. a Expression of CCR4 ligands in the lungs of uninfected and $\mathrm{PbN}$-infected WT mice was evaluated by qPCR. b Quantification of CCL2 by ELISA from homogenate originated from lungs of C57BL/6 mice. c Histogram showing CCR2 and CCR4 expression by monocyte-derived cells $\left(\mathrm{F} 4 / 80^{+} \mathrm{CD} 11 \mathrm{~b}^{+}\right)$harvested from uninfected and infected C57BL/6 mice (top panel). Graphs indicating MFI of the CCR2 and CCR4 expression by $\mathrm{F} 4 / 80^{+} \mathrm{CD} 11 \mathrm{~b}^{+}$that refers to the representative

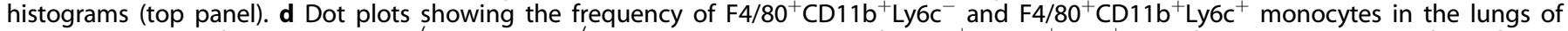
control and $\mathrm{PbN}$-infected $\mathrm{WT}, \mathrm{CCR} 2^{-/-}$, and CCR4 ${ }^{-/-}$mice. e Total number of $\mathrm{F} 4 / 80^{+} \mathrm{CD} 11 \mathrm{~b}^{+} \mathrm{Ly}_{6 \mathrm{c}^{+}}$cells found in the lungs of uninfected controls and $\mathrm{PbN}$-infected WT, CCR2 ${ }^{-1-}$, and CCR4 ${ }^{-1-}$ mice. f Survival curve of CCR2 ${ }^{-1-}, \mathrm{CCR} 4^{-/-}$, and WT mice after challenge with PbN. Data (a-e) are representative of at least two independent experiments ( $n=4-6$ mice per group)

the early stage of $P b N$ infection (Fig. 6b). Indeed, we found that emergence of $\mathrm{F} 4 / 80^{+} \mathrm{CD} 11 \mathrm{~b}^{+} \mathrm{Ly}_{6 \mathrm{c}^{+}}$(counter plots) expressing DCsign (histogram) in the lungs of $\mathrm{NOS}^{-1-}$ mice was similar to that observed in WT mice infected with $\mathrm{PbN}$ (Fig. 6c, bottom right panel). We also investigated the frequency of $\mathrm{NOS}^{+}$cells in the lungs of infected WT mice. Our results indicate that Tip-DCs are the most important NOS2 expressing cells in the lungs from $\mathrm{PbN}$ infected mice (Fig. 6d).

TNFa has been shown to induce NOS2 expression. Hence, TNFR1 $1^{-1-}$ mice were infected with $P b N$. In contrast to NOS2 ${ }^{-l-}$, the TNFR1 ${ }^{-1-}$ mice were not resistent to MA-ARDS/ALI (Figure S10A). Importantly, the monocytes derived from NOS2 ${ }^{-1-}$ produced TNF- $a$, in similar levels to monocytes from infected
C57BL/6 mice. Likewise, the monocytes derived cells from mice deficient to TNFR1 receptor were capable to produce NOS2 similar to WT mice (Figure 10B and C), futher suggesting that TNFa is not involved in the pathogenesis of MA-ARDS/ALI in this model.

The results of lung damage, histopathology, parasitemia, and parasite load in the lungs in different knockout lineages are summarized in Figure S11. It is noteworthy that we observe no correlation with parasitism and lung pathology, indicating that tissue inflammation is the main cause of MA-ARDS/ALI. Altogether, our results indicate that during infection with $P b N$, monocytes differentiate into MO-DC that migrate to the lungs in a CCR4dependent manner. The MO-DCs are then activated by IFN- $\gamma$ producing $\mathrm{CD}^{+} \mathrm{T}$ cells and differentiate into Tip-DC, which are 
A

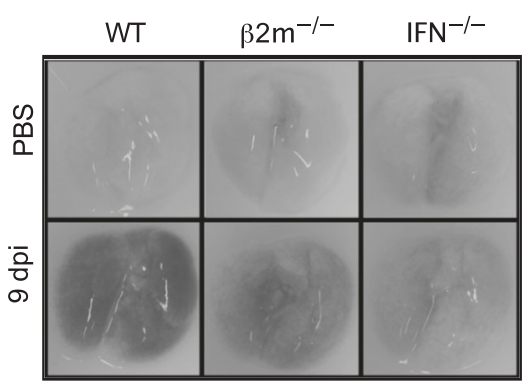

C

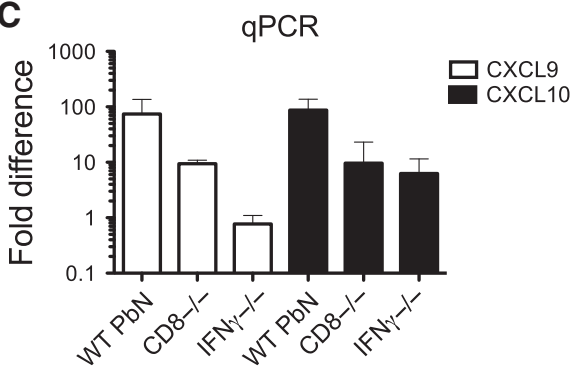

B

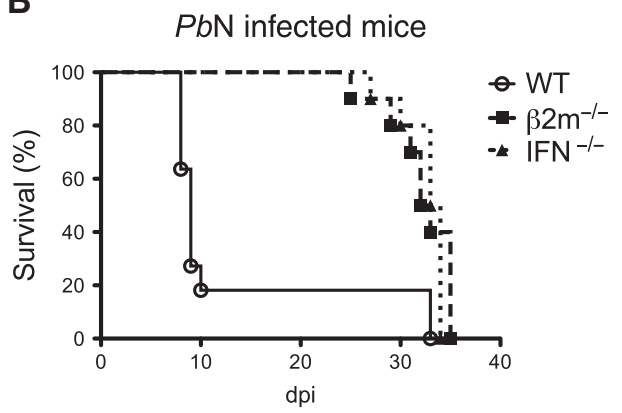

D

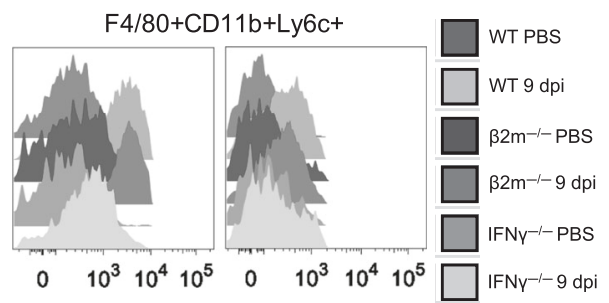

E
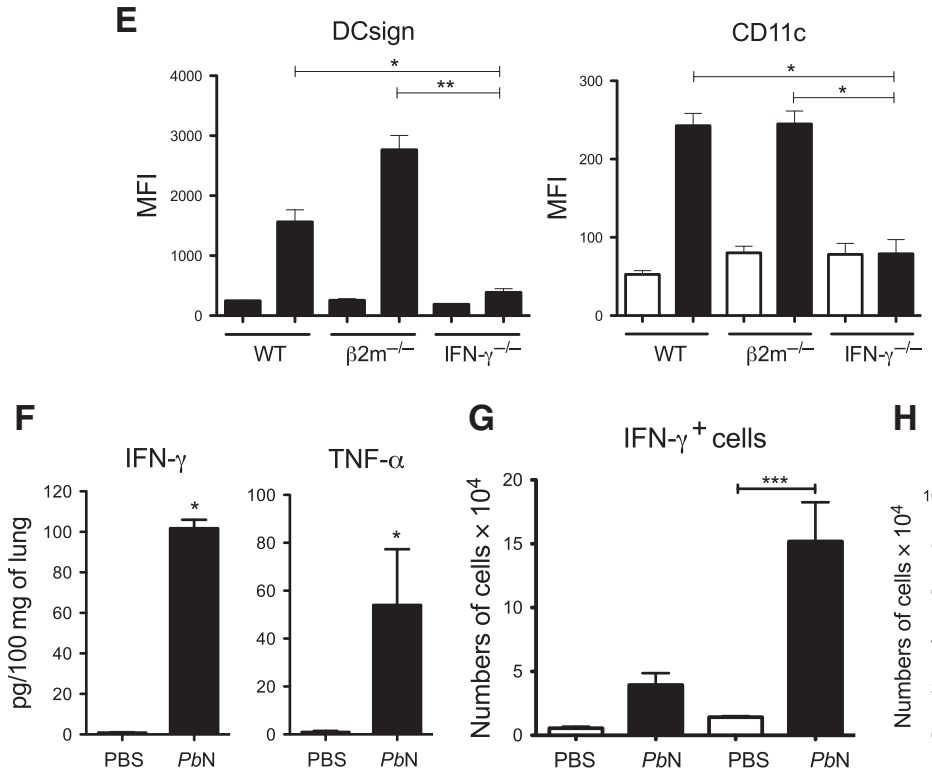

G

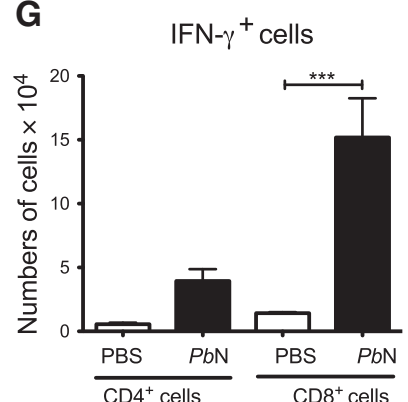

H $\mathrm{F}_{4} / 80^{+} \mathrm{CD}^{-11 \mathrm{~b}^{+} \mathrm{Ly} 6 \mathrm{C}} \mathrm{C}^{+}$

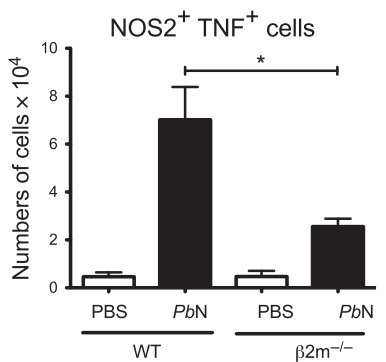

Fig. $5 \mathrm{CD} 8^{+} \mathrm{T}$ cells and endogenous IFN- $\gamma$ are necessary for monocyte derived dendritic cells differentiation and activation as well as lung damage. a MA-ARDS/ALI-induced hemorrhage is attenuated in the lungs of $P b N$-infected $\beta 2$-microglobulin ${ }^{-1-}$ and IFN- $\gamma^{-1-}$ mice, compared to WT mice. b Delayed mortality in PbN-infected WT, $\beta 2$-microglobulin ${ }^{-1-}$, and IFN- $\gamma^{-1-}$ mice. $\mathbf{c}$ Expression of CXCL9 and CXCL10 mRNA in the lungs of uninfected and $P b N$-infected WT, $\beta 2$-microglobulin ${ }^{-1}$, and IFN $-\gamma^{-1-}$ mice. d Histogram illustrating the expression of DCsign (left

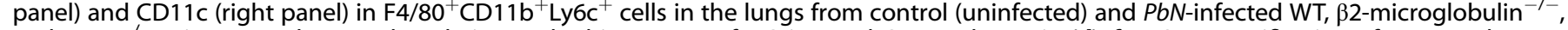
and IFN- $\gamma^{-1-}$ mice. e MFI bar graphs relative to the histograms of DCsign and CD11c shown in (d). $\mathbf{f}$ ELISA quantification of IFN- $\gamma$ and TNF- $\alpha$ levels in lung homogenates from control and $P b N$-infected WT mice. $\mathbf{f}$ Number of IFN- $\gamma$ producing $C D 4^{+} \mathrm{T}_{\text {and }} \mathrm{CD} 8^{+} \mathrm{T}$ cells from lungs of control and PbN-infected C57BL/6 mice. g Numbers of CD11 b ${ }^{+} \mathrm{Ly \sigma c}^{+} \mathrm{TNF}^{+} \mathrm{NOS2}^{+}$cells (Tip-DCs) from WT and 2-microglobulin ${ }^{-1-}$ mice. Data (a-g) are representative of two independent experiments ( $n=4-5$ mice per group)

the effector cells mediating lung tissue damage during MA-ARDS/ $\mathrm{ALI}$ through the production of reactive nitrogen species.

\section{DISCUSSION}

In this study we demonstrate that CCR4 plays a central role in mediating lung damage in MA-ARDS/ALI model, which is typically characterized by the presence of Th1 and $\mathrm{CD} 8^{+} \mathrm{T}$ lymphocytes and IFN- $\gamma$ dependent immune response. ${ }^{34,35}$ Indeed, we demonstrate that the majority of infiltrating activated $\mathrm{CD}^{+}$and $\mathrm{CD}^{+} \mathrm{T}$ cells in the lungs from $\mathrm{PbN}$-infected mice express both CXCR3 and Tbet, which are indicative of IFN- $\gamma$ producing T cells. ${ }^{36}$ We also identified a group of myeloid cells with phenotype similar to MO-DCs (CD11 $\left.\mathrm{c}^{+} \mathrm{CD} 11 \mathrm{~b}^{+} \mathrm{F} 4 / 80^{+} \mathrm{DCsign}^{+}\right)$that express high levels of TNF-a and iNOS, similar to Tip-DCs. ${ }^{29}$ The requirement of CCR4 in this model was unexpected, since most studies indicate a role of CCR4 in Th2-mediated immune responses. We hypothesize that during $P b N$ infection, CCR4 mediates migration of MO-DCs to 


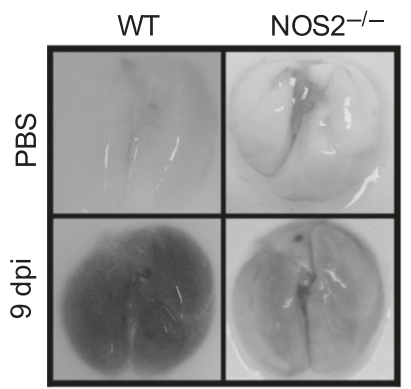

C

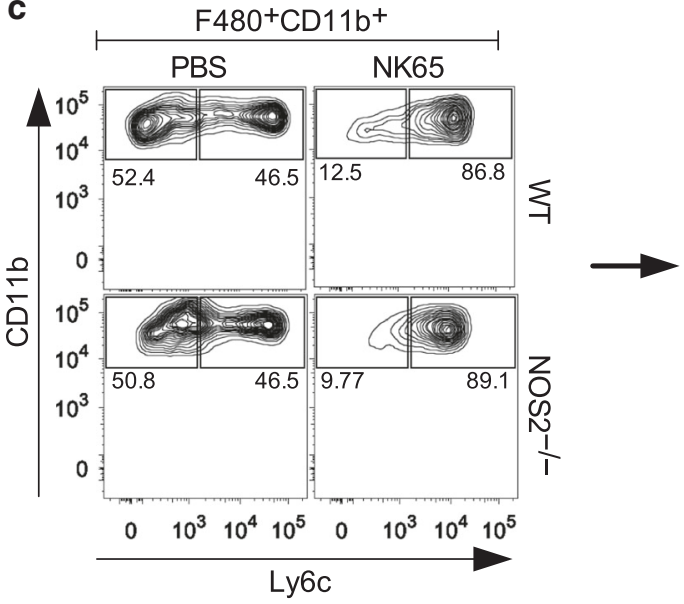

b

$\mathrm{PbN}$ infected mice

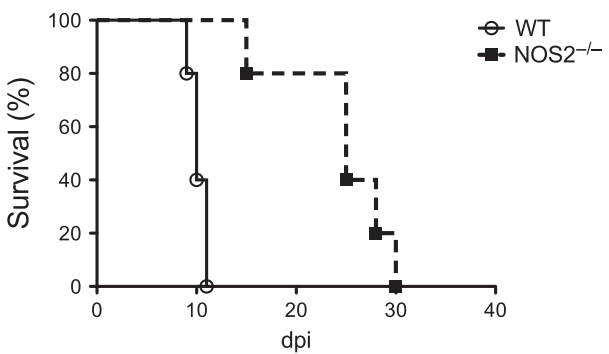

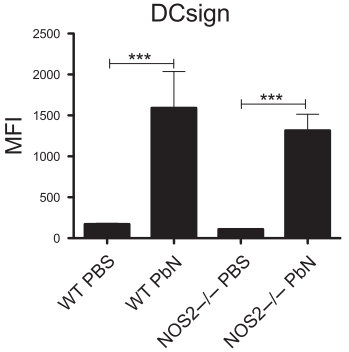
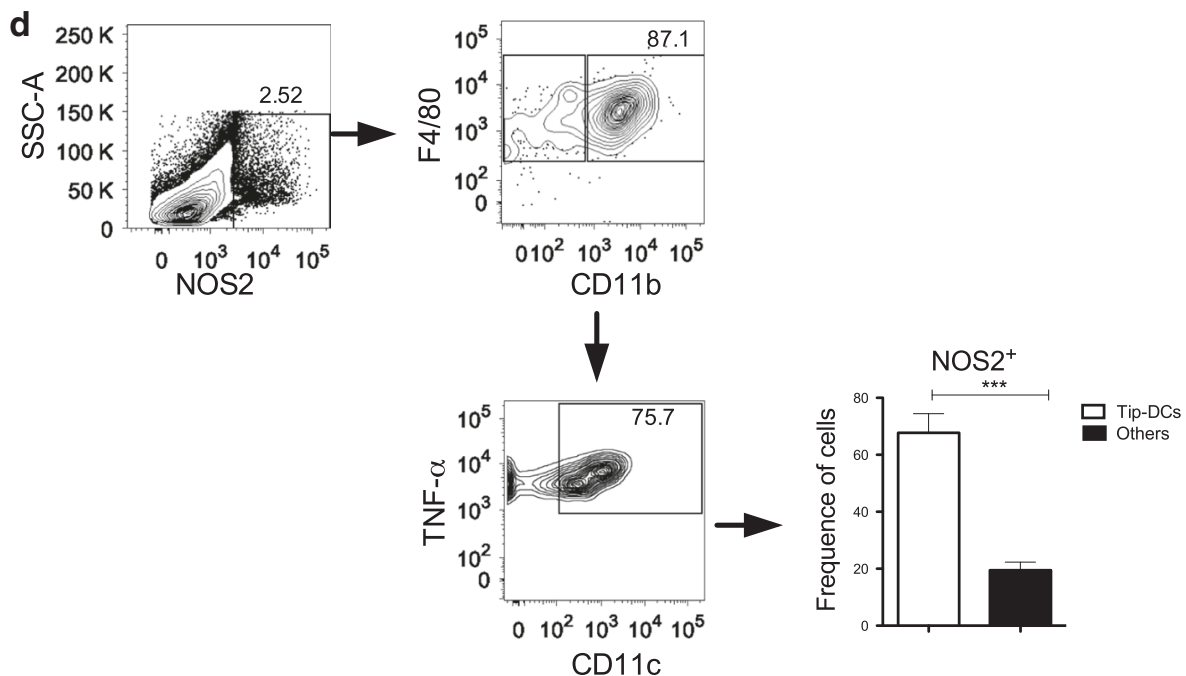

Fig. $6 \mathrm{NOS2}^{-1-}$ mice are resistant to $\mathrm{PbN}$-induced MA-ARDS/ALI. a Lungs from uninfected (top quadrants) and $\mathrm{PbN}$-infected (bottom quadrants) WT and NOS2 ${ }^{-1-}$ mice. b Survival curves of WT and NOS2 $2^{-1-}$ mice infected with PbN. c Dot plot showing the frequency of F4/ $80^{+} \mathrm{CD} 11 \mathrm{~b}^{+} \mathrm{Ly}_{6 \mathrm{c}^{+}}$cells in WT and NOS2 ${ }^{-1-}$ mice. Histogram showing the DCsign expression (right, top panel) and MFI graph (right, bottom panel) of $\mathrm{F} 4 / 80^{+} \mathrm{CD} 11 \mathrm{~b}^{+} \mathrm{Ly}_{6 \mathrm{c}^{+}}$cells from lungs of control and $\mathrm{PbN}$-infected WT and NOS2${ }^{-1-}$ mice. d Gate strategy (dot plots) to quantify the frequency of $\mathrm{NOS}^{+}$expressing cells. Graph indicates the frequency of Tip-DCs (F4/80 ${ }^{+} \mathrm{CD} 11 \mathrm{~b}^{+} \mathrm{CD} 11 \mathrm{c}^{+} \mathrm{TNF}-\alpha^{+} \mathrm{NOS} 2^{+}$) compared to non-TipDC leukocyte populations that express NOS2 in the lungs of WT infected mice. Data (a-d) are representative of two independent experiments ( $n=4-5$ mice per group).

the lungs, where they differentiate into Tip-DC in a $\mathrm{CD}^{+} \mathrm{T}^{-}$celland IFN- $\gamma$ dependent manner. Finally, our results suggest that TipDC are the main effector cells and NOS2 a key metabolic enzyme that mediates tissue damage and development of MA-ARDS/ALI.

Importantly, our results show that while CCR4 play a key role, CCR2 deficiency does not impact on MA- ARDS/ALI development. Different from CCR4, $\beta 2 m$, IFN- $\gamma$, and NOS2 deficient mice, $\mathrm{CCR}^{-1-}$ mice showed lung damage and lethality similar to WT mice. Importantly, parasitemia and parasite load in the lungs in the various knockout, including the $\mathrm{CCR}^{-1-}$ mice, and WT mice did not correlate with development of MA-ARDS/ALI. Hence, we assume that the main cause of MA-ARDS/ALI is the inflammation induced by $\mathrm{PbN}$ infection, rather than direct tissue damage caused directly by the parasite.

CCR2 has been implicated in monocyte egress from bone marrow and distribution to lymphoid organs. Indeed, we found 
that the frequency and number of monocytes was lower, both in blood and spleen of control and infected CCR2 ${ }^{-/-}$. Intriguingly, the lower number of monocytes in peripheral lymphoid organ did not impact in the development of tissue lung damage. While monocyte migration to the lungs of $\mathrm{CCR}^{-1-}$ mice was delayed, at 9 days post-infection the frequency and number of MO-DCs in the lungs were similar to that found in WT mice. We also found an increased numbers of neutrophils in the lung from infected $\mathrm{CCR}^{-1-}$ mice, which may contribute to lung tissue damage and lethality. Our results with $\mathrm{CCR}^{-1-}$ mice are somewhat consistent with data obtained from another model ( $P$. berghei ANKA) of MAARDS/ALI. Similar to our results at day 5 and 7 post-infection, they found an impaired migration of inflammatory monocytes on day 6 post-infection. In addition, CCR2 ${ }^{-/-}$were still highly susceptible to MA-ARDS/ALI, contrasting with $\mathrm{CD}^{-1-}$ that were highly resistent. ${ }^{37}$

In sharp contrast with $\mathrm{CCR}^{-1-}$ mice infected with $P b N$, the frequency of monocytes in the blood and spleen of CCR4 ${ }^{-1-}$ was similar to WT mice, whereas the migration of MO-DCs was severily impaired in all time points. Hence, we conclude that while CCR2 contributes to monocyte egress from bone marrow and homing of these cells in peripheral lymphoid organs, it is the CCR4 that mediate the migration of monocytic cells to the lungs of $\mathrm{PbN}$ infected mice.

Importantly, CCR4 was shown to influence macrophages and Th2 lymphocytes recruitment and the development of pulmonary fibrosis. ${ }^{38}$ However, we found that expression of CCL17 and CCL22 was very low in the lungs of $P b N$ infected mice. Nevertheless, we observed that expression of CCL2 and CCL3 mRNA are enhanced in the lungs of $P b N$-infected mice. CCL2 chemokine was previously described to mediate $T$ cell migration in a CCR4-dependent manner. ${ }^{39,40}$ Consistently, the first study that described the $\mathrm{CCR}^{-1-}$ mice, it was observed that in a LPS-induced septic shock, macrophage migration to the peritoneal site was partially dependent on CCR4. This same work showed that splenocytes and thymocytes isolated from the $\mathrm{CCR}^{-1-}$ mice failed to respond to the CCL3 ${ }^{41}$ In addition, in a Th1/Th17-mediated experimental autoimmune encephalomyelitis model (EAE), GMCSF/IL-23 producing dendritic cells are activated via CCR4. ${ }^{42}$ Hence, our results suggests that other CCR4 ligands different from CCL17 and CCL22 are acting on leukocyte recruitment during $\mathrm{Th} 1$ and $\mathrm{CD}^{+} \mathrm{T}$ cells mediated inflammation, and this needs to be further investigated.

The importance of $\mathrm{CD}^{+} \mathrm{T}$ cells in MA-ARDS/ALI was studied before, but the mechanisms by which these cells mediate lung tissue damage have not been defined. ${ }^{17}$ We confirmed that both CD8 and IFN- $\gamma$ deficient mice are resistant to MA-ARDS/ALI induced by $P b N$. However, the migration of $C D 8^{+} \mathrm{T}$ cells to the lungs was not affected in the CCR4 ${ }^{-1-}$ mice infected with $\mathrm{PbN}$. Hence, our results indicate that in this model, $C D 8^{+}$T cells play an indirect role in lung tissue damage. In addition, we found that IFN$\gamma$, but not $\mathrm{CD}^{+} \mathrm{T}$ cells, was essential for the presence of mature MO-DCs $\left(C D 11 b^{+} \mathrm{Ly}_{6 \mathrm{C}^{+}} \mathrm{CD} 11 \mathrm{c}^{+} \mathrm{DCsign}{ }^{+}\right)$in the lungs of $\mathrm{PbN}$ infected mice.

It is known that mice deficient in NOS2 are resistant to bleomycin-induced lung injury. ${ }^{43}$ Importantly, we found that $\mathrm{PbN}$ infected $\beta 2$-microglobulin ${ }^{-1-}$ mice have reduced number of Tip$\mathrm{DC}$, when compared to C57BL/6 mice. Furthermore, $\mathrm{PbN}$-infected $\mathrm{NOS2}^{-1-}$ mice were shown to be resistant to MA-ARDS/ALI and TNFa seems no to be involved on NOS2 mediated lung injury, since $\mathrm{F} 4 / 80^{+} \mathrm{CD} 11 \mathrm{~b}^{+} \mathrm{Ly}_{6 \mathrm{c}^{+}}$cells from TNFR1 ${ }^{-1-}$ mice expressin normal levels of NOS2 when compare to infected WT mice. In contrast, Tip-DCs do not differentiate in IFNy mice, which are resistant to MA-ARDS/ALI. Importantly, we found that over $94 \%$ of IFN $\gamma^{+}$cells in the lungs and more than $98 \%$ of IFN- $\gamma^{+}$cells in the spleen are $\mathrm{CD}^{+} \mathrm{T}$ cells.

Our results are distinct from those obtained with another mouse model of MA-ARDS/ALI using DBA-2 mice infected with $\mathrm{PbA}$. In this model, neutrophil extracellular traps (NETs), myeloperoxidase and reactive oxygen species are the main mediators of lung damage. ${ }^{44}$ However, lung injury in malaria patients is associated with high frequency of monocytes, macrophages, and lymphocytes, whereas neutrophils are less frequent cells. ${ }^{45}$ Furthermore, consistent with Tip-DC phenotype, TNF-a production is associated with NOS2 expression in $P$. falciparum malaria patients. ${ }^{46}$ In addition, a single nucleotide polymorphism on NOS2 appears to influence the development of severe malaria. ${ }^{47}$

Importantly, targeting CCR4 has been used as important therapeutic intervention in different experimental models of Th2-mediated pathology and cancer cells. For instance, the use of a CCR4 antagonist effectively attenuated allergic lung inflammation in mice. ${ }^{48}$ In a renal cancer model, the use of CCR4 antagonist resulted in a reduced immature myeloid cell infiltrate and increased numbers of NK cells. ${ }^{49}$ Furthermore, CCR4 is expressed in hepathocellular carcinoma in humans and has been proposed as therapeutic target. ${ }^{50}$

In conclusion, our results highlight the importance of CCR4 on migration of MO-DCs in MA-ARDS/ALI, which is mediated by Type 1 immune responses. Our data suggest that the CCR4 ligands CCL2 and CCL3, but not CCL17 and CCL22, play the key role in the MO-DC recruitment to the lung of $P b N$-infected mice. In addition, we speculate that IFN- $\gamma$ locally produced by $\mathrm{CD}^{+} \mathrm{T}$ cells induces the final differentiation of MO-DC to TipDC, which in turn mediate tissue pathology by producing high levels of reactive nitrogen species. Finally, MA-ARDS/ALI seems to be inflammatory disease induced by sequestration of infected erythrocytes. If our findings are validated in humans undergoing acute episode of malaria, they provide a new insight for therapeutic intervention of MAARDS/ALI.

\section{ACKNOWLEDGEMENTS}

This work was supported by the National Institutes of Health (R01Al079293, R01NS098747, R21Al131632); Brazilian National Institute of Science and Technology for Vaccines granted by Conselho Nacional de Desenvolvimento Ciêntífico e Tecnológico (CNPq)/Fundação de Amparo a Pesquisa do Estado de Minas Gerais (Fapemig)/Coordenação de Aperfeiçoamento de Pessoal de Ensino Superior (CAPES) (465293/2014-0); and CNPq (PQ - 307408/2016-7 and 301031/2015-0). We also acknowledge the Program for Technological Development in Tools for Health, PDTIS -FIOCRUZ for the use of its facilities.

\section{AUTHOR CONTRIBUTIONS}

B.G.F., J.T, M.M.F. and C.G.R. performed experiments; B.G.F., J.T., M.M.F., R.T.G. and L.R.V.A. analyzed the data; B.G.F., R.T.G. and L.R.V.A. designed experiments, discussed the data and wrote the manuscript.

\section{ADDITIONAL INFORMATION}

The online version of this article (https://doi.org/10.1038/s41385-018-0093-5) contains supplementary material, which is available to authorized users.

Competing interests: The authors declare no competing interests.

\section{REFERENCES}

1. WHO. World Malaria Report, 2016

2. Gazzinelli, R. T., Kalantari, P., Fitzgerald, K. A. \& Golenbock, D. T. Innate sensing of malaria parasites. Nat. Rev. Immunol. 14, 744-757 (2014).

3. Wang, W. et al. Monoclonal antibody against CXCL-10/IP-10 ameliorates influenza A (H1N1) virus induced acute lung injury. Cell Res. 23, 577-580 (2013).

4. Salihefendic, N., Zildzic, M. \& Ahmetagic, S. Acute Respiratory Distress Syndrome (ARDS) from Endemic Influenza A/H1N1: Prehospital Management. Med. Arch. 69, 62-63 (2015)

5. Maguire, G. P. et al. Lung injury in uncomplicated and severe falciparum malaria: a longitudinal study in papua, Indonesia. J. Infect. Dis. 192, 1966-1974 (2005). 
6. Hanson, J. P. et al. Fluid resuscitation of adults with severe falciparum malaria: effects on acid-base status, renal function, and extravascular lung water. Crit. Care Med. 41, 972-981 (2013)

7. Atam, V., Singh, A. S., Yathish, B. E. \& Das, L. Acute pancreatitis and acute respiratory distress syndrome complicating Plasmodium vivax malaria. J. Vector Borne. Dis. 50, 151-154 (2013).

8. Lee, H. J. et al. A case of vivax malaria complicated by adult respiratory distress syndrome and successful management with extracorporeal membrane oxygenation. Korean J. Parasitol. 51, 551-555 (2013).

9. Habib, A. G. \& Singh, K. S. Respiratory distress in nonimmune adults with imported malaria. Infection 32, 356-359 (2004).

10. Nayak, K. C. et al. A study on pulmonary manifestations in patients with malaria from northwestern India (Bikaner). J. Vector Borne. Dis. 48, 219-223 (2011).

11. Anstey, N. M. et al. Lung injury in vivax malaria: pathophysiological evidence for pulmonary vascular sequestration and posttreatment alveolar-capillary inflammation. J. Infect. Dis. 195, 589-596 (2007).

12. Faustino, $L$. et al. Regulatory $T$ cells migrate to airways via CCR4 and attenuate the severity of airway allergic inflammation. J. Immunol. 190, 2614-2621 (2013).

13. Panina-Bordignon, $\mathrm{P}$. et al. The $\mathrm{C}-\mathrm{C}$ chemokine receptors $\mathrm{CCR} 4$ and $C \mathrm{CR} 8$ identify airway $\mathrm{T}$ cells of allergen-challenged atopic asthmatics. J. Clin. Invest. 107, 1357-1364 (2001)

14. Maruyama, T. et al. CCL17 and CCL22 chemokines within tumor microenvironment are related to infiltration of regulatory $T$ cells in esophageal squamous cell carcinoma. Dis. Esophagus 23, 422-429 (2010).

15. Riezu-Boj, J. I. et al. Hepatitis C virus induces the expression of CCL17 and CCL22 chemokines that attract regulatory $T$ cells to the site of infection. J. Hepatol. 54, 422-431 (2011).

16. Power, C. A. et al. Molecular cloning and functional expression of a novel CC chemokine receptor cDNA from a human basophilic cell line. J. Biol. Chem. 270, 19495-19500 (1995).

17. Van den Steen, P. E. et al. Immunopathology and dexamethasone therapy in a new model for malaria-associated acute respiratory distress syndrome. Am. J. Respir. Crit. Care. Med. 181, 957-968 (2010).

18. Deroost, K. et al. Hemozoin induces lung inflammation and correlates with malaria-associated acute respiratory distress syndrome. Am. J. Respir. Cell Mol. Biol. 48, 589-600 (2013).

19. Scaccabarozzi, D. et al. Altered lipid composition of surfactant and lung tissue in murine experimental malaria-associated acute respiratory distress syndrome. PLoS ONE 10, e0143195 (2015)

20. Pereira, M. L. et al. Association of heme oxygenase 1 with lung protection in malaria-associated ALI/ARDS. Mediators Inflamm. 2016;2016:4158698

21. Villegas-Mendez, A. et al. Heterogeneous and tissue-specific regulation of effector T cell responses by IFN-gamma during Plasmodium berghei ANKA infection. J. Immunol. 187, 2885-2897 (2011).

22. Chang, W. L. et al. CD8(+)-T-cell depletion ameliorates circulatory shock in Plasmodium berghei-infected mice. Infect. Immun. 69, 7341-7348 (2001).

23. Goldszmid, R. S. et al. NK cell-derived interferon-gamma orchestrates cellular dynamics and the differentiation of monocytes into dendritic cells at the site of infection. Immunity 36, 1047-1059 (2012).

24. Dabritz, J. et al. Reprogramming of monocytes by GM-CSF contributes to regulatory immune functions during intestinal inflammation. J. Immunol. 194, 2424-2438 (2015)

25. Hirako, I. C. et al. Splenic differentiation and emergence of CCR5+CXCL9 $+\mathrm{CXCL} 10+$ monocyte-derived dendritic cells in the brain during cerebral malaria. Nat. Commun. 7, 13277 (2016).

26. Jacobs, R. L. Role of P-aminobenzoic acid in Plasmodium Berghei infection in the mouse. Exp. Parasitol. 15, 213-225 (1964).

27. Zhang, Y., Merali, S. \& Meshnick, S. R. p-Aminobenzoic acid transport by normal and Plasmodium falciparum-infected erythrocytes. Mol. Biochem. Parasitol. 52, 185-194 (1992).
28. Antonelli, L. R. et al. Intranasal Poly-IC treatment exacerbates tuberculosis in mice through the pulmonary recruitment of a pathogen-permissive monocyte/macrophage population. J. Clin. Invest. 120, 1674-1682 (2010).

29. Serbina, N. V., Salazar-Mather, T. P., Biron, C. A., Kuziel, W. A. \& Pamer, E. G. TNF/ iNOS-producing dendritic cells mediate innate immune defense against bacterial infection. Immunity 19, 59-70 (2003).

30. Sponaas, A. M. et al. Migrating monocytes recruited to the spleen play an important role in control of blood stage malaria. Blood 114, 5522-5531 (2009).

31. Campanella, G. S. et al. Chemokine receptor CXCR3 and its ligands CXCL9 and CXCL10 are required for the development of murine cerebral malaria. Proc. Natl Acad. Sci. USA 105, 4814-4819 (2008).

32. Cheong, C. et al. Microbial stimulation fully differentiates monocytes to DC-SIGN/ CD209(+) dendritic cells for immune T cell areas. Cell 143, 416-429 (2010).

33. Blanchette, J., Jaramillo, M. \& Olivier, M. Signalling events involved in interferongamma-inducible macrophage nitric oxide generation. Immunology 108, 513-522 (2003)

34. Nie, C. Q., Bernard, N. J., Schofield, L. \& Hansen, D. S. CD4+CD25+regulatory T cells suppress $\mathrm{CD} 4+\mathrm{T}$-cell function and inhibit the development of Plasmodium berghei-specific $\mathrm{TH} 1$ responses involved in cerebral malaria pathogenesis. Infect. Immun. 75, 2275-2282 (2007).

35. Findlay, E. G. et al. Essential role for IL-27 receptor signaling in prevention of Th1mediated immunopathology during malaria infection. J. Immunol. 185, 2482-2492 (2010)

36. Koch, M. A. et al. The transcription factor T-bet controls regulatory $\mathrm{T}$ cell homeostasis and function during type 1 inflammation. Nat. Immunol. 10, 595-602 (2009)

37. Lagasse, H. A. et al. Recruited monocytes modulate malaria-induced lung injury through CD36-mediated clearance of sequestered infected erythrocytes. J. Leukoc. Biol. 99, 659-671 (2016).

38. Belperio, J. A. et al. The role of the Th2 CC chemokine ligand CCL17 in pulmonary fibrosis. J. Immunol. 173, 4692-4698 (2004).

39. Brown, C. E. et al. Tumor-derived chemokine MCP-1/CCL2 is sufficient for mediating tumor tropism of adoptively transferred T cells. J. Immunol. 179, 3332-3341 (2007)

40. Sun, W. et al. Blockade of MCP-1/CCR4 signaling-induced recruitment of activated regulatory cells evokes an antitumor immune response in head and neck squamous cell carcinoma. Oncotarget 7, 37714-37727 (2016).

41. Chvatchko, Y. et al. A key role for CC chemokine receptor 4 in lipopolysaccharideinduced endotoxic shock. J. Exp. Med. 191, 1755-1764 (2000).

42. Poppensieker, K. et al. CC chemokine receptor 4 is required for experimental autoimmune encephalomyelitis by regulating GM-CSF and IL-23 production in dendritic cells. Proc. Natl Acad. Sci. USA 109, 3897-3902 (2012).

43. Genovese, T. et al. Inhibition or knock out of inducible nitric oxide synthase result in resistance to bleomycin-induced lung injury. Respir. Res. 6, 58 (2005).

44. Sercundes, M. K. et al. Targeting neutrophils to prevent malaria-associated acute lung injury/acute respiratory distress syndrome in mice. PLoS Pathog. 12, e1006054 (2016).

45. Valecha, N. et al. Histopathology of fatal respiratory distress caused by Plasmodium vivax malaria. Am. J. Trop. Med. Hyg. 81, 758-762 (2009).

46. Rockett, K. A., Awburn, M. M., Rockett, E. J., Cowden, W. B. \& Clark, I. A. Possible role of nitric oxide in malarial immunosuppression. Parasite Immunol. 16, 243-249 (1994)

47. Cramer, J. P. et al. iNOS promoter variants and severe malaria in Ghanaian children. Trop. Med. Int. Health 9, 1074-1080 (2004).

48. Zhang, Y. et al. A new antagonist for CCR4 attenuates allergic lung inflammation in a mouse model of asthma. Sci. Rep. 7, 15038 (2017).

49. Berlato, C. et al. A CCR4 antagonist reverses the tumor-promoting microenvironment of renal cancer. J. Clin. Invest. 127, 801-813 (2017). 2007;179:19962004

50. Cheng, X. et al. Up-regulation of chemokine receptor CCR4 is associated with Human Hepatocellular Carcinoma malignant behavior. Sci. Rep. 7, 12362 (2017). 